\title{
Proceeding
}

Supplementary Issue: Spring Conferences of Sports Science. 15th Convention and Workshop of the International Network of Sport and Health Science, 5-8 June 2019. University of Las Palmas de Gran Canaria, Las Palmas de Gran Canaria, Spain.

\section{The use of enabling tests to provide a qualitative measurement of the sport skill level of small soccer players}

\author{
GIOVANNI ESPOSITO ${ }^{1}$, ROSARIO CERUSO ${ }^{1}$, MANUELA VALENTINI², TIZIANA D'ISANTO1 \\ ${ }^{1}$ Department of Human, Philosophical and Education Sciences, University of Salerno, Italy \\ 2Department of Human and Education Sciences, University of Carlo Bo of Urbino, Italy
}

\begin{abstract}
Evaluation tests represent a fundamental step in the educational path of working with small football players. The method used is of an experimental type whose aim is to analyse the capacity of children in the execution of three fundamental technical aspects of football: Short and Long Passage, Header shot and Shot on Target from a stationary position and in movement. We want to emphasize the importance of training the technical gesture starting from the little ones. In fact, too much tacticism combined with a continuous search for physicality in every area of the field has produced in the last decade an innumerable series of technically poorly trained players. The tests were performed on a sample of 12 children of 10 years old that play championship under-10. The data shows the score from each child during the execution of the various tests from which the total result was obtained by adding the points awarded for each attempt. The average of the high scores for the various tests was 13 for short pass; 27.3 for long pass; 3.6 for the header shot $t ; 9.6$, and 7.75 respectively for stationary and moving shot on goal. The results can be used at the beginning of the activity and when a new group is available to identify the gaps to work on and then they can be repeated in other and different periods of the season to verify how effective the work done up to that point was. Keywords: Header shot; Shot on target; Short and long passage.

\section{Cite this article as:}

Esposito, G., Ceruso, R., Valentini, M., \& D'Isanto, T. (2019). The use of enabling tests to provide a qualitative measurement of the sport skill level of small soccer players. Journal of Human Sport and Exercise, 14(4proc), S592-S601. doi:https://doi.org/10.14198/ihse.2019.14.Proc4.17

Corresponding author. Department of Human, Philosophical and Education Sciences, University of Salerno, Italy.

E-mail: g.esposito198@studenti.unisa.it

Supplementary Issue: Spring Conferences of Sports Science. 15th Convention and Workshop of the International Network of Sport and Health Science, 5-8 June 2019. University of Las Palmas de Gran Canaria, Las Palmas de Gran Canaria, Spain. JOURNAL OF HUMAN SPORT \& EXERCISE ISSN 1988-5202

(c) Faculty of Education. University of Alicante doi:10.14198/jhse.2019.14.Proc4.17
\end{abstract}




\section{INTRODUCTION}

In football as well as in other physical and sporting disciplines, trainers have as their main objective to advance their players thanks to sessions, whose quality level will encourage real learning (Arcelli 1978). If we define learning as the improvement of physical actions after several identical sessions, we realize that the concept of repetition is fundamental (Raiola 2017). In view of a constant improvement of the players, the educator's task will then be to propose exercises that they will feel they can perform on the condition of concentrating and engaging in the realization of the gesture (Ceruso et al. 2019). It will be then necessary, during the various attempts, to provide the players with precise technical instructions, bringing them to the path of success (Raiola, Di Tore 2017). The real goal will be, after analysing the level and potential of its players, to enable each educator to propose varied and suitable sessions in order to generate continuous progressions and an optimization in the training of his players (Altavilla et al. 2018).

The trainer must be able to observe and understand the needs of the young player to improve his shortcomings or enhance his qualities (Valentini et al. 2018). The technique can be defined as a skill or a set of skills; in practice, it is a series of actions performed without conscious control, which allow the player to carry out the movements required by the sporting discipline practiced with great confidence and ease (Di Tore, Raiola 2012). The football technique, in particular, is a set of movements, with or without the ball that the player takes during the game (Altavilla, Raiola 2019). From a didactic point of view, the improvement of the player from a technical-tactical point of view, and under that inherent to the development of his dexterity, for the purposes of the game, cannot prescind from the position and attitude of the comrades, as well as from the from the position and behaviour of the opponents. However, the technique in analytical form is of fundamental importance, namely that of the movements with the ball, which is called "fundamental technique"(Odasso et al. 1984). Even if the training must be oriented mainly towards exercises, that is, proposals closely related to the game situations, it is a mistake not to work on the executions of the different gestures, i.e. without the presence of the opponent, or to improve "the relationship man-ball". What, this is essential to be able to manage the tool in the game situations themselves (Di Salvo et al. 2007).

Functional assessment is the prerequisite for training control, using tests in which certain variables are measured (D'santo et al. 2019). These trials are commonly referred to as tests, where the word test is synonymous with measure. The most important variables for measuring performance in team sports, such as football, are physical conditions and technical and tactical performance (Reilly, Holmes 1983). However, due to the complexity of the game of football, it is difficult to ascertain the relative importance of each of these variables. The test is an indicator, more or less reliable, of a quality or capacity that one intends to investigate, so it must be analysed and interpreted by an expert in the sport in question. Weineck (2009), in turn, defines the test as an indispensable tool for the programming of training processes whether they be short, medium or long term, which also allows diagnosing any insufficiencies that cannot always be grasped by the simple observation of game.

In the literature, there are several classifications of these tests. The three most common ones concern the division between general and specific tests, that between laboratory tests and field tests and finally that between continuous and discontinuous tests. As indicated by Dal Monte (1983), the general tests go to investigate the organic-muscular abilities, the general coordination abilities and the state of health, with the purpose of evaluating the physical form of the athlete in question. Specific tests, on the other hand, analyse the specific coordination skills with the aim of evaluating the technical-tactical component. Regarding the classification indicated by MacDougall et al. (1991), the variable considered concerns the place where these tests are carried out; the tests carried out in the laboratory are generally more standardized but less specific 
unlike the field ones, and require the presence of highly qualified personnel. Instead, field tests are relatively simple to perform, easily accessible to everyone, with the possibility of being offered at any time. Finally, the last classification investigates the different intensity modalities with which these tests can be administered; based on the type of intensity that can be expressed, the exercise can be administered continuously, or discontinuously or intermittently.

Regardless of the type of test applied, each of these must guarantee three fundamental requirements that verifying the validity of the information collected.

These requirements, defined as precision, must be demonstrated experimentally for each test before their implementation. The three requirements are:

- Validity

- Reliability

- Objectivity

A result is valid when the information obtained from the test accurately measures the variable or quality that you intend to actually measure. A result is reliable if, starting from similar conditions, it will be repeated at different times. A result is objective, when two different operators find the same result (Mazzeo, Raiola 2018). To obtain tests that meet these three main requirements, it is necessary that the method of administration is of a standardized type; in practice, the tests must always be performed with the same protocol and must include the same heating or execution methods (Marella, Risaliti 1999).

The use of field tests in the youth sectors allows, as it happens for the first teams, to detect some fundamental parameters for the trainer (Bell 1988). First of all it is important to know if the training intervention was effective and if all the players involved have benefited equally (Beunen et al. 1981), then also wanting to consider the aggregation of new components in a rose or the return to group of boys after a period of injury, it is also necessary to establish how their physical fitness levels differ from the rest of the team (Rosch et al. 2000).

In the moment in which the results obtained by the boys in the tests are evaluated, it is appropriate however that the trainer, in addition to knowing the biological age of the subject, should also consider the variability of some parameters during the growth period that are due in part to changes in body size and partly to changes in some physiological functions (Bar-Or and Rowland).

For the purposes of the research dealt with in the following chapter, ball-using tests were used. Obviously, these tests have a very important technical component and therefore they are proposed to verify the impact of the specific technique on some characteristics of the player.

\section{METHODS AND MATERIALS}

\section{Subjects}

The research was carried out on a group of 12 athletes of 11 years old, belonging to the team of U.S Salernitana that are competing in the under-10 provincial championship. They play their matches at the «V. Volpe» sports centre (SA). 


\section{Experimental design}

Aim of the study is to recruit the qualitative data on the performance aspects about of reutilize to rearrangement of training planning.

In particular, we want to emphasize the importance of training the technical gesture from the little ones (Altavilla, Raiola 2018). In fact, too much tacticism combined with a continuous search for physicality in every area of the field has produced in the last decade an innumerable series of technically poorly trained players with very little knowledge of the offensive game, because since young the culture of victory reigns supreme at detriment of any kind of training (Raiola 2013).

The method used is of an experimental type whose aim is to analyse the capacity of children in the execution of three fundamental technical aspects of football:

- Short and Long Passage

- Header shot

- Shot on Target from a stationary position

- Shot on Target in movement

These tests are among the eight technical tests proposed by the F-MARC battery (Rosch et al. 2000) and investigate what are considered the most important football techniques.

The first test carried out is that of the "long pass", where the player must make a shot, trying to hit a circle of $2 \mathrm{~m}$ radius placed inside a square of $10 \mathrm{~m}$ on the side. The distance between the point where the player must hit the ball and the centre of the circle is $36 \mathrm{~m}$. After making a test roll, five tests are performed and 3 points are awarded if the ball falls into the circle and 1 point if it falls out of the same circle, but inside the square. The first ball bounce is considered. The test provides information on the accuracy of the long shot.

The second test investigates "short passage" where the player leads the ball in a $4 \mathrm{~m}$ long rectangle at the end of which he must pull towards a small door $(90 \mathrm{~cm}$ long and $60 \mathrm{~cm}$ high) placed at $11 \mathrm{~m}$ distance. Five trials are made, assigning 3 points if he score a goal and 1 point if the ball hits the door without entering.

The next test is that of a shot on goal with dead ball. The player must make a shot, from a distance of $15 \mathrm{~m}$. The target is subdivided into six sectors and the ball must enter into the top right or top left corner. There are three trials for each of the two target sectors and 3 points are awarded if the ball enters the established space, 1 point if the ball hits the crossbar or the post in the established sector and 1 point if the ball enters at the top of central sector.

Is then the turn of the shot on goal after receiving a pass. Here the player must receive a pass from a teammate, from the side of the penalty area (about $20 \mathrm{~m}$ ) towards the line delimiting the area. From here, he moves towards the penalty spot, and take a shot on goal. Also in this test, the target is divided into 6 sectors and the ball must enter the sector at the top right or in the top left corner. There are three trials for each of the two target sectors and 6 points are awarded if the ball enters the predetermined sector, 1 point if the ball hits the post or crossbar, 2 points if the ball enters the central sector at the top and 1 point if enter one of the 3 sectors below the door. If the passage is not accurate, the test is not valid.

The last test to be performed is that of the "header shot". It can be administered in two ways. The first one foresees that the operator, placed at $3 \mathrm{~m}$ ahead of the goal line and in front of the player, throws the ball 
towards the latter who, from the penalty spot, must score, directing the ball in one of the two target sectors, the one on the top right or the top left. There are three trials for each of the two target sectors and 6 points are awarded if the ball enters the predetermined sector, 1 point if the ball hits the crossbar or the post within the predetermined sector, 3 points if the ball enters the sector below right or left. If the examiner's throwing of the ball is not accurate, the test is invalid.

In the second mode, the examiner throws the ball from the right side of the area towards the player, who must walk $3 \mathrm{~m}$ before hitting the ball with the head near the penalty spot. The scoring mode and the number of trials are identical to that of the first mode. In both modes, a test is performed before starting the trial.

\section{RESULTS}

Table 1. Short pass test

\begin{tabular}{lrrrrrr}
\hline Trials & $\mathbf{1}^{\mathbf{0}}$ & $\mathbf{2}^{\circ}$ & $\mathbf{3}^{\circ}$ & $\mathbf{4}^{\circ}$ & $\mathbf{5}^{\circ}$ & Total \\
\hline Player 1 & 3 & 3 & 3 & 1 & 3 & 13 \\
Player 2 & 3 & 3 & 3 & 3 & 3 & 15 \\
Player 3 & 3 & 3 & 3 & 3 & 3 & 15 \\
Player 4 & 3 & 3 & 3 & 3 & 3 & 15 \\
Player 5 & 0 & 3 & 3 & 3 & 3 & 12 \\
Player 6 & 0 & 3 & 0 & 3 & 3 & 9 \\
Player 7 & 3 & 1 & 3 & 3 & 0 & 10 \\
Player 8 & 3 & 3 & 3 & 3 & 3 & 15 \\
Player 9 & 3 & 3 & 0 & 3 & 3 & 12 \\
Player 10 & 3 & 3 & 3 & 3 & 3 & 15 \\
Player 11 & 3 & 3 & 3 & 3 & 3 & 15 \\
Player 12 & 0 & 3 & 3 & 3 & 1 & 10 \\
\hline
\end{tabular}

Table 2. Long pass test

\begin{tabular}{lrrrrrrr}
\hline Trials & $\mathbf{1}^{\mathbf{0}}$ & $\mathbf{2}^{\circ}$ & $\mathbf{3}^{\circ}$ & $\mathbf{4}^{\circ}$ & $\mathbf{5}^{\circ}$ & $6^{\circ}$ & Total \\
\hline Player 1 & 3 & 6 & 6 & 6 & 6 & 6 & 33 \\
Player 2 & 6 & 6 & 6 & 6 & 1 & 6 & 31 \\
Player 3 & 6 & 6 & 6 & 6 & 6 & 6 & 36 \\
Player 4 & 3 & 3 & 6 & 6 & 3 & 6 & 27 \\
Player 5 & 3 & 3 & 3 & 6 & 6 & 3 & 27 \\
Player 6 & 6 & 6 & 6 & 6 & 6 & 3 & 33 \\
Player 7 & 3 & 0 & 1 & 3 & 3 & 3 & 15 \\
Player 8 & 6 & 6 & 0 & 6 & 3 & 6 & 33 \\
Player 9 & 3 & 3 & 6 & 6 & 6 & 6 & 30 \\
Player 10 & 6 & 3 & 6 & 6 & 6 & 6 & 33 \\
Player 11 & 6 & 3 & 6 & 3 & 3 & 3 & 21 \\
Player 12 & 0 & 0 & 3 & 3 & 0 & 3 & 9 \\
\hline
\end{tabular}


Table 3. Header shot test

\begin{tabular}{lccccccr}
\hline Trials & $\mathbf{1}^{\mathbf{0}}$ & $\mathbf{2}^{\mathbf{0}}$ & $\mathbf{3}^{\mathbf{0}}$ & $\mathbf{4}^{\mathbf{0}}$ & $\mathbf{5}^{\mathbf{0}}$ & $\mathbf{6}^{\mathbf{0}}$ & Total \\
\hline Player 1 & 0 & 1 & 1 & 2 & 3 & 1 & 8 \\
Player 2 & 3 & 3 & 0 & 1 & 1 & 3 & 11 \\
Player 3 & 1 & 3 & 3 & 3 & 2 & 3 & 15 \\
Player 4 & 0 & 2 & 1 & 2 & 1 & 3 & 9 \\
Player 5 & 0 & 0 & 1 & 1 & 0 & 1 & 3 \\
Player 6 & 2 & 3 & 3 & 1 & 3 & 3 & 15 \\
Player 7 & 3 & 3 & 1 & 1 & 0 & 2 & 10 \\
Player 8 & 2 & 3 & 3 & 0 & 3 & 2 & 13 \\
Player 9 & 1 & 1 & 0 & 0 & 2 & 3 & 7 \\
Player 10 & 3 & 3 & 2 & 1 & 0 & 0 & 9 \\
Player 11 & 3 & 3 & 2 & 3 & 1 & 1 & 13 \\
Player 12 & 0 & 0 & 1 & 0 & 1 & 1 & 3 \\
\hline
\end{tabular}

Table 4. Shot on target from a stationary position

\begin{tabular}{lrrrrrr}
\hline Trials & $\mathbf{1}^{\mathbf{0}}$ & $\mathbf{2}^{\circ}$ & $\mathbf{3}^{\circ}$ & $\mathbf{4}^{\circ}$ & $\mathbf{5}^{\circ}$ & Total \\
\hline Player 1 & 0 & 0 & 1 & 0 & 0 & 1 \\
Player 2 & 3 & 0 & 1 & 0 & 0 & 4 \\
Player 3 & 0 & 3 & 3 & 3 & 1 & 10 \\
Player 4 & 0 & 1 & 0 & 1 & 3 & 5 \\
Player 5 & 0 & 1 & 0 & 1 & 0 & 2 \\
Player 6 & 1 & 3 & 0 & 1 & 3 & 8 \\
Player 7 & 0 & 0 & 0 & 0 & 0 & 0 \\
Player 8 & 1 & 3 & 1 & 0 & 0 & 5 \\
Player 9 & 0 & 1 & 0 & 1 & 0 & 2 \\
Player 10 & 1 & 0 & 3 & 0 & 0 & 4 \\
Player 11 & 0 & 1 & 1 & 0 & 0 & 2 \\
Player 12 & 0 & 1 & 0 & 0 & 0 & 1 \\
\hline
\end{tabular}


Table 5. Shot on target in movement

\begin{tabular}{lccccccr}
\hline Trials & $\mathbf{1}^{\mathbf{0}}$ & $\mathbf{2}^{\mathbf{0}}$ & $\mathbf{3}^{\mathbf{0}}$ & $\mathbf{4}^{\mathbf{0}}$ & $\mathbf{5}^{\mathbf{0}}$ & $6^{\mathbf{0}}$ & Total \\
\hline Player 1 & 1 & 1 & 0 & 1 & 1 & 0 & 4 \\
Player 2 & 1 & 3 & 1 & 2 & 2 & 2 & 11 \\
Player 3 & 3 & 2 & 1 & 0 & 3 & 1 & 10 \\
Player 4 & 0 & 1 & 1 & 1 & 2 & 1 & 6 \\
Player 5 & 1 & 0 & 0 & 0 & 1 & 1 & 3 \\
Player 6 & 3 & 3 & 1 & 0 & 1 & 1 & 9 \\
Player 7 & 3 & 2 & 1 & 1 & 1 & 3 & 11 \\
Player 8 & 2 & 3 & 0 & 2 & 1 & 1 & 9 \\
Player 9 & 0 & 1 & 3 & 3 & 0 & 3 & 10 \\
Player 10 & 1 & 1 & 3 & 1 & 1 & 0 & 7 \\
Player 11 & 3 & 1 & 2 & 3 & 0 & 1 & 10 \\
Player 12 & 0 & 1 & 1 & 0 & 0 & 1 & 3 \\
\hline
\end{tabular}

\section{DISCUSSION}

This study sought to investigate the qualitative data of the performance inherent to the football technique, to be able to use them for the reorganization of the planning of training sessions. To this end, an experimental investigation was conducted using different tests, used to verify the influence of various skills on the performance of the players. These tests were administered to twelve boys, thus creating a representative sample of the age group (11-12 years) examined.

The reason these tests were developed are varied. In fact, through these field tests, the trainer can understand if his footballer is able or not to use that particular fundamental of football, then from the evaluation of these tests he will be able to go to work on the limits of the subject with the appropriate training methods (Rago et al. 2017). Moreover, from these tests we can also note the mental aspect of the subject, from how he reacts when he is under pressure or when he has to prove something (Raiola, Rago 2014). These tests can also be useful for the instructor to understand in a certain period of the season, which of his players are in better shape, especially in terms of mentality.

The results of the tests showed the existence of a high variability in terms of performance among young players, caused by genetic and environmental factors as well as their previous skills. This result is consistent with the expectation initially expressed in the elaborate, according to which the development of the individual is characterized as a unique, individualized and personal fact different from person to person. A possible confirmation of these results can be provided by the research of Malina et al (2003) where they analyse in detail that the variations in the execution of physical tasks, are represented by 21 to $50 \%$ by the size of the body, by the stage of sexual maturity and by the years of training. Even Le Gall et al (2008), with their research, offer a realistic overview of the analysed group, believing that the performance of the tests may vary according to age group and game position.

The present paper complements the existing literature, as previous studies had already provided insights that have determined widespread training methodologies. Based on these studies, numerous debates were also born on the training of fundamentals in football. Although the theories that put physical training in football 
first are often in contradiction with each other, in the past the trainers have become, as D'Arrigo (2018) says, "Slaves of football-related science" (Giordano et al. 2019). Today it is unthinkable to separate the physical preparation from the natural preparation of the technical-tactical game that allows, in itself a real physical improvement when the training proposals are organized effectively (D'Elia et al. 2019).

However, it is important to keep in mind that this research has focused exclusively on certain elements that characterize the performance. Further study on the relevance of specific protocols and training tests at different ages during adolescence would be needed. It would be advisable to compare the measures through the subsequent years of development of the participants, as many of the physical qualities that distinguish players may not be evident until late adolescence, although any further improvements in players may be confused due to prolonged training. Secondly, the number of tests performed was limited because the battery in question was administered during the competitive season in preparation for the meetings and therefore there were strong demands in terms of training time.

A recommendation for further future research could be to carry out a similar study to identify, for those who have the possibility, directly the physiological capabilities rather than relying on performance-based estimates, focusing in detail on this specific element.

\section{CONCLUSION}

Ultimately, we can consider functional evaluation as a necessary and indispensable method that allows positive feedback not only to the trainer but also to the kids themselves. In fact, in addition to providing the trainer a real-time feedback on the development status of the players' structures and functions, it is also necessary to recognize the educational value of the assessment, since it allows children to acquire knowledge of their own body and above all of their own limits, through the awareness of their level of physical form.

\section{REFERENCES}

Altavilla, G., Mazzeo, F., D’Elia, F., Raiola, G. (2018) Physical commitment and specific work for each role in an elite soccer team, Journal of Physical Education and Sport, 18 (2), 570-574.

Altavilla, G., Raiola, G. (2019), A brief review on physiological commitment in basketball: An interpretative key, Journal of Human Sport and Exercise, 14, pp. S59-S65. https://doi.org/10.14198//hse.2019.14.proc1.07

Altavilla, G., Gaetano, R. (2018), Physiological effects of warm-up and problems related to team sports, Sport Science, 11, pp. 83-88.

Arcelli, E. Considerazioni di tipo fisiologico sulla preparazione atletica dei calciatori, in "Notiziario del Settore Tecnico FIGC", n. 7, luglio 1978.

Bar-Or, O., \& Rowland, T. W., Pediatric exercise medicine, Human Kinetics, Champaign Illinois 2004.

Bell, W., Physiological characteristics of 12-year-old soccer players, In Reilly, T., Lees, A., Davids, K., \& Murphy, W.J., Science and football, Taylor \& Francis, 1988.

Beunen, G., Ostyn, M., Simons, J., Renson, R., \& Van Gerven, D., Chronological and biological age as related to physical fitness in boys 12 to 19 years, in "Annals of Human Biology", n. 8.4, 1981. https://doi.org/10.1080/03014468100005121

Ceruso, R., Esposito, G., Federici, A., Valentini, M., D'isanto, T., Preliminary work about the basis data for monitoring youth soccer team planning training (2019), Journal of Human Sport and Exercise, 14 (Proc2), pp. S251-S257. https://doi.org/10.14198//hse.2019.14.proc2.14 
D’Arrigo, F., Il primato del gioco, la comunicazione didattica del calcio. La Casa Usher, 2018.

D'Elia, F., D'Isanto, T., \& Altavilla, G. (2019). Training and performance in the transition period. Journal $\begin{array}{llll}\text { of Human Sport and Exercise, 14(2proc), S258-S262. } & \end{array}$ https://doi.org/10.14198/ihse.2019.14.Proc2.15

Dal Monte, Antonio. La valutazione funzionale dell'atleta. Sansoni Editore, 1983.

D'Isanto, T., D'Elia, F., Raiola, G., Altavilla, G. (2019). Assessment of sport performance: theoretical aspects and practical indications. Sport Mont, 17(1), 79-82. https://doi.org/10.26773/smj.190214

Di Salvo, V., Baron, R., Tschan, H., Montero, F. C., Bachl, N., \& Pigozzi, F. (2007). Performance characteristics according to playing position in elite soccer. International journal of sports medicine, 28(03), 222-227. https://doi.org/10.1055/s-2006-924294

Di Tore, P.A., Raiola, G. (2012) Exergames in motor skill learning, Journal of Physical Education and Sport, 12 (3), 358-361.

Gaetano, R., Rago, V. (2014) Preliminary study on effects of hiit-high intensity intermittent training in youth soccer players, Journal of Physical Education and Sport, 14 (2), pp. 148-150.

Giordano, L., Federici, A., Valentini, M., D'elia, F. (2019) Dribbling in football: Confronting learning theories, Journal of Human Sport and Exercise, 14 (Proc2), pp. S228-S232. https://doi.org/10.14198/ihse.2019.14.proc2.10

Le Gall, F., Carling, C., Williams, M., \& Reilly, T., Anthropometric and fitness characteristics of international, professional and amateur male graduate soccer players from an elite youth academy, in "Journal of Science and Medicine in Sport", n.13, 2010. https://doi.org/10.1016/j.jsams.2008.07.004

MacDougall, J. D., Wenger, H. A., \& Green, H. J., Physiological testing of the high- performance (II ed.), Human Kinetics, Champaign Illinois 1991.

Malina, M., Eisenmann, J. C., Cumming, S. P., Ribeiro, B., \& Aroso, J., Maturity- associated variation in the growth and functional capacities of youth football (soccer) players 13-15 years, in "Journal of Applied Physiology", n. 91, 2004. https://doi.org/10.1007/s00421-003-0995-z

Marella, M., \& Risaliti, M., II libro dei test. Le prove di valutazione fisica per tutti gli sport, Edizioni Correre, Milano 2007.

Mazzeo, F., Raiola, G. (2018), An investigation of drugs abuse in sport performance, Journal of Human Sport and Exercise, 13, pp. S309-S319. https://doi.org/10.14198/ihse.2018.13.proc2.15

Odasso, A. Trucchi, G., Vatta, S., L'allenamento calcistico. Ricerca della condizione per mezzo di esercitazioni tecniche, Tipo Velox Edizioni Torino pp. 155-156, 1984.

Rago, V., Pizzuto, F., Raiola, G. (2017) Relationship between intermittent endurance capacity and match performance according to the playing position in sub-19 professional male football players: Preliminary results, Journal of Physical Education and Sport, 17 (2), pp. 688-691.

Raiola, G. (2017) Motor learning and teaching method, Journal of Physical Education and Sport, 17, 2239-2243.

Raiola, G., Di Tore, P.A. (2017) Motor learning in sports science: Different theoretical frameworks for different teaching methods [Motoričko učenje u sportskoj znanosti: Različiti teorijski okviri za različite metode poučavanja] Sport Science, 10, 50-56.

Raiola, G. (2013) Body knowledge and motor skills, nKnowledge Cultures, 1 (6), pp. 64-72.

Rampinini, E., Bishop, D., Marcora, S., Ferranti Bravo, D., Sassi, R., \& Impellizzeri, F. M., Validity of simple field test as indicators of match related physical performance in tol level professional soccer players, in "International Journal of Sports Medicine", n. 28.03, 2007. https://doi.org/10.1055/s-2006924340

Reilly, T., \& Ball, D., The net physiological cost of dribbling a soccer ball, in "Research Quarterly for Exercise and Sports", n. 55.3, 1984. https://doi.org/10.1080/02701367.1984.10609363 
Reilly, T., \& Holmes, M., A preliminary analysis of selected soccer skills, in "Physical Education Review", n. 6.1, 1983.

Reilly, T., Nevill, A. M., \& Franks, A., A multidisciplinary approach to talent identification in soccer, in "Journal of Sports Sciences", n. 18.9., 2000. https://doi.org/10.1080/02640410050120078

Rosch, D., Hodgson, R., Peterson, L., Graf-Baumann, T., Junge, A., Chomiak, J., \& Dvorak, J., Assessment and evaluation of football performance, in "American Journal of Sports Medicine", n. 28.5, 2000. https://doi.org/10.1177/28.suppl 5.s-29

Valentini, M., Riccardi, F., Raiola, G., Federici, A. (2018), Educational research: Motor area and relational area during children's personality development, Journal of Physical Education and Sport, 18, 2157 2174.

Weineck, Jürgen. L'allenamento ottimale: una teoria dell'allenamento basata sui principi della fisiologia del movimento, con particolare riferimento all'allenamento infantile e giovanile. Calzetti-Mariucci, 2009. https://doi.org/10.1007/978-88-470-1187-8_2 